\title{
Small airways disease: time for a revisit?
}

This article was published in the following Dove Press journal:

International Journal of COPD

7 August 2017

Number of times this article has been viewed

\author{
James A Stockley' \\ Brendan G Cooper' \\ Robert A Stockley ${ }^{2}$ \\ Elizabeth Sapey ${ }^{3}$ \\ 'Department of Lung Function \\ and Sleep, ${ }^{2}$ Department of \\ Respiratory Medicine, University \\ Hospital Birmingham, ${ }^{3}$ Institute of \\ Inflammation and Ageing, Centre for \\ Translational Inflammation Research, \\ University of Birmingham, Edgbaston, \\ Birmingham, UK
}

Abstract: It is increasingly acknowledged that delays in the diagnosis of chronic inflammatory lung conditions have hampered our understanding of pathogenesis and thus our ability to design efficacious therapies. This is particularly true for COPD, where most patients are diagnosed with moderate-to-severe airflow obstruction and little is known about the inflammatory processes present in early disease. There is great interest in developing screening tests that can identify those most at risk of developing COPD before airflow obstruction has developed for the purpose of research and clinical care. Landmark pathology studies have suggested that damage to the small airways precedes the development of airflow obstruction and emphysema and, thus, presents an opportunity to identify those at risk of COPD. However, despite a number of physiological tests being available to assess small airways function, none have been adopted into routine care in COPD. The reasons that tests of small airways have not been utilized widely include variability in test results and a lack of validated reference ranges from which to compare results for some methodologies. Furthermore, population studies have not consistently demonstrated their ability to diagnose disease. However, the landscape may be changing. As the equipment that delivers tests of small airways become more widely available, reference ranges are emerging and newer methodologies specifically seek to address variability and difficulty in test performance. Moreover, there is evidence that while tests of small airways may not be helpful across the full range of established disease severity, there may be specific groups (particularly those with early disease) where they might be informative. In this review, commonly utilized tests of small airways are critically appraised to highlight why these tests may be important, how they can be used and what knowledge gaps remain for their use in COPD.

Keywords: small airways, COPD, early disease, physiology, emphysema, airflow obstruction

\section{Introduction}

The small airways (usually defined as those with an internal diameter of $\leq 2 \mathrm{~mm}$ ) are recognized as the major site of resistance to airflow in obstructive lung disease. The direct physiological support for this came from the classical study of Hogg et al, ${ }^{1}$ and subsequent pathological studies confirmed a generalized decrease in diameter of the small airways in smokers with established airflow obstruction. ${ }^{2}$ However, it was recognized that pathological changes in the small airways, although related to expiratory airflow obstruction, ${ }^{3}$ could occur in the absence of spirometric impairment that is diagnostic of COPD. This led to the concept of small airways representing the "silent zone" of lung disease (the site of early lung damage without recognized airflow obstruction or, necessarily, symptoms), which, in turn, led to the development and validation of new physiological tests aimed at detecting abnormalities in peripheral airways and the associated resistance to airflow. Such tests were developed to explore the concept of "early disease", and it was argued that they could identify subjects at risk of future development of COPD. Indeed, some studies provided evidence supporting this concept, ${ }^{4}$ whereas others reported the opposite. ${ }^{5,6}$ These results, therefore,
Correspondence: Elizabeth Sapey Institute of Inflammation and Ageing, Centre for Translational Inflammation Research, University of Birmingham, Edgbaston, Birmingham BI5 2GW, UK Tel/fax +44 I2I 6272000 Email e.sapey@bham.ac.uk
International Journal of COPD 20I7:12 2343-2353

2343

Dovepress f $y$ in $\mathbf{0}$

http://dx.doi.org/10.21471COPD.S138540 (c) (1) (8) 2017 Stockley et al. This work is published and licensed by Dove Medical Press Limited. The full terms of this license are available at https://www.dovepress.com/terms.php cc. ${ }_{\mathrm{BY}} \mathrm{NC}$ and incorporate the Creative Commons Attribution - Non Commercial (unported, v3.0) License (http://creativecommons.org/licenses/by-nch/3.0/). By accessing the work you hereby accept the Terms. Non-commercial uses of the work are permitted without any further permission from Dove Medical Press Limited, provided the work is properly attributed. For permission for commercial use of this work, please see paragraphs 4.2 and 5 of our Terms (https://www.dovepress.com/terms.php). 
questioned the utility of the tests in subject assessment and prognosis, which hindered their general usage.

In recent years, there has been a resurgence of interest in the study of small airways from a pathophysiological viewpoint and even for clinical management. The ability to phenotype patients with COPD in more detail has led to further interest in the emphysematous lung. Emphysema is associated with both airflow obstruction and, importantly, a more rapid subsequent decline in the forced expiratory volume in one second $\left(\mathrm{FEV}_{1}\right),{ }^{7,8}$ increased mortality ${ }^{9}$ and prevalence of lung cancer. ${ }^{10}$ The more comprehensive pathological studies reported by Hogg and colleagues ${ }^{11,12}$ have highlighted (albeit cross-sectionally) evidence that significant loss of small airways also precedes the pathological evidence of emphysema. In support of this concept, a recent study in alpha-1 antitrypsin deficiency (AATD), which is an emphysema-dominant COPD phenotype, found maximal mid-expiratory flow (MMEF) (as a surrogate of small airways function) preceded both the spirometric evidence of COPD and detection of emphysema by computed tomography. In addition, abnormal tests were associated with impaired health status and predicted the subsequent rate of decline of $\mathrm{FEV}_{1} \cdot{ }^{13}$

Detecting early physiological abnormality in the small airways is challenging for a number of reasons. First, while the majority of tests available may be affected by small airway dysfunction, they do not necessarily assess the small airways exclusively and may also be influenced by abnormality in the larger airways. For instance, measures of global airway resistance (Raw) may be influenced by increased resistance of the small or large airways. Furthermore, abnormality (such as obstruction) in the larger airways may render the small airways less accessible with physiological testing. Second, due to the vast number of small airways, a widespread dysfunction may be required before physiological abnormality is detectable. Finally, unlike routine lung function tests (such as spirometry and gas transfer), many physiological tests of small airway function do not currently have robust reference ranges, making it more difficult to define "abnormality". It is also important to differentiate between small airways disease (specific pathology), small airways dysfunction (quantifiable physiological abnormality) and early disease (early pathological changes that may or may not occur in the small airways).

As with all chronic diseases, early detection and development of preventative strategies is important in the prevention or abrogation of the long-term sequelae and health care consequences of COPD. The use of validated and robust tests of small airways function will likely play a key role in this strategy. Therefore, the purpose of the current review is to explore the role of previous and newer tests of small airways function, their potential strengths and weaknesses in identifying subjects at risk of developing COPD and their use/proposed use in patient monitoring and response to treatment.

\section{Spirometry}

Spirometry is an assessment of pulmonary ventilation and currently defines the presence of COPD with a reduction in the $\mathrm{FEV}_{1}$ /forced vital capacity (FVC) ratio according to the Global Initiative for Chronic Obstructive Lung Disease (GOLD) strategy document. ${ }^{14}$ It is the most widely used and accessible lung function test, and the $\mathrm{FEV}_{1}$ is the most common parameter used prognostically for monitoring and as a primary outcome for interventional trials in COPD. Although spirometry provides robust information about established pathology and its progression, routine spirometric parameters are of limited value, especially in early disease. For example, spirometry is recognized as a poor surrogate for emphysema, which may be present even when the $\mathrm{FEV}_{1}$ and FVC are within the normal range. ${ }^{15}$ As small airways disease has also been shown to precede the development of emphysema, ${ }^{16}$ this supports the concept that routine spirometry would be insensitive to early changes in the small airways as the pathological processes of COPD develop.

\section{Expiratory flows}

Early airway changes in COPD most commonly occur in the peripheral regions of the lungs at the level of the terminal bronchioles. ${ }^{1}$ Throughout the expiratory curve, flow measurements may be taken at different intervals that reflect airflow through different airways. These include maximal expiratory flow when $75 \%$ of $\mathrm{FVC}$ remains $\left(\mathrm{MEF}_{75}\right)$, maximal expiratory flow when $50 \%$ of FVC remains $\left(\mathrm{MEF}_{50}\right)$, maximal expiratory flow when $25 \%$ of $\mathrm{FVC}$ remains $\left(\mathrm{MEF}_{25}\right)$ and the MMEF (between 75 and 25\% of FVC) (Figure 1).

Leuallen and Fowler ${ }^{17}$ first introduced the MMEF as a test of ventilation that was particularly sensitive to expiratory airflow obstruction. This parameter has been the most widely studied to date. Recently, Tsushima et al ${ }^{18}$ described a significantly lower percentage predicted MMEF in GOLD Stage 0 COPD (patients "at risk" of COPD who are symptomatic but have a normal $\mathrm{FEV}_{1} / \mathrm{FVC}$ ) than in healthy (asymptomatic) subjects. MMEF/FVC has also been found to be lower in these patients considered at risk of COPD than in healthy individuals, although higher than in those with established COPD. ${ }^{19}$ 


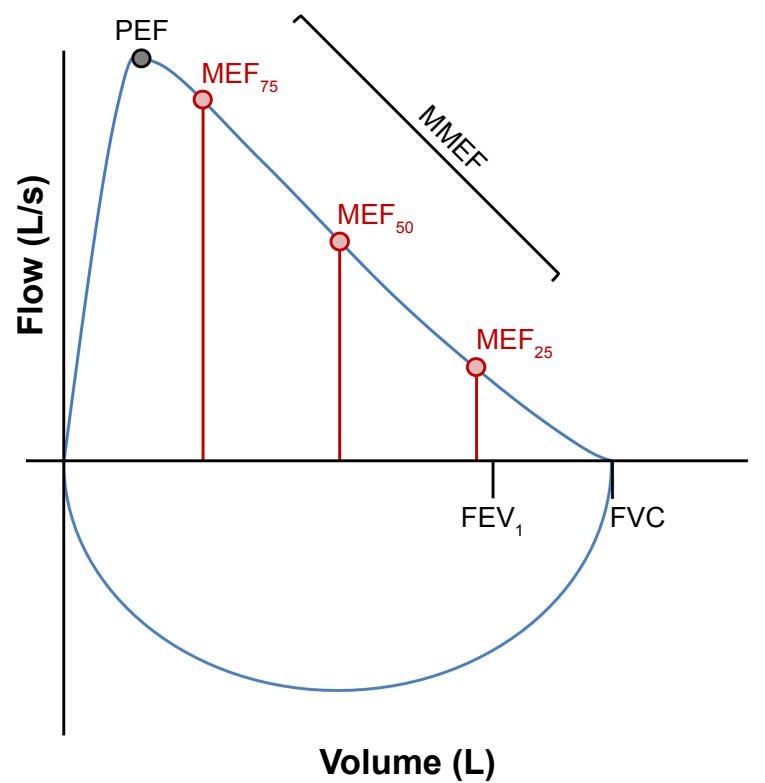

Figure I Graphical representation of a flow-volume loop indicating the traditional parameters ( $F E V$, and FVC) and the various flow parameters measured at intervals throughout the forced expiratory curve.

Abbreviations: $\mathrm{FEV}_{1}$, the forced expiratory volume in one second; FVC, forced vital capacity; MMEF, maximal mid-expiratory flow; $\mathrm{MEF}_{25}$, maximal expiratory flow when $25 \%$ of $\mathrm{FVC}$ remains; $\mathrm{MEF}_{50}$, maximal expiratory flow when $50 \%$ of $\mathrm{FVC}$ remains; $\mathrm{MEF}_{75}$, maximal expiratory flow when $75 \%$ of $\mathrm{FVC}$ remains; PEF, peak expiratory flow.

However, it should be noted that MMEF is highly dependent on FVC and may, therefore, be reduced in the absence of airflow limitation when a patient's lungs are smaller than average for their age, sex, height and race. Therefore, MMEF requires cautious interpretation, and as such, its usefulness in general clinical practice has generally been discounted. ${ }^{20}$ For serial measurements, it has been suggested that the dependency of MMEF on FVC may be overcome by measuring it iso-volumetrically (at the same lung volume), ${ }^{21,22}$ although this requires more specialized equipment. However, despite the limitations of MMEF, it may still be useful as a stand-alone measure in certain patient cohorts as a marker of early airflow limitation before the spirometric criterion for COPD is reached. ${ }^{13,23}$ Topalovic et $\mathrm{al}^{23}$ extended this concept by analyzing the shape of the flow-volume curve and demonstrated that the angle of inflection between the two best fitting regression lines of the expiratory curve with a cutoff angle of $<131^{\circ}$ was highly specific (97\%), although less sensitive (51\%), for the presence of emphysema in COPD. This angle of inflection (or "spirographic kink") reflects the dynamic airways collapse due to the loss of lung connective tissue in emphysema (notably elastin) that usually maintains airway patency during forced expiration in healthy individuals. ${ }^{24,25}$

An alternative approach has been proposed to compare the FVC (a forced maneuver) with a relaxed vital capacity (VC) maneuver, which overcomes (at least partly) the dynamic airways collapse associated with damaged small airways and supporting connective tissue loss. Barros et $\mathrm{al}^{26}$ assessed this by measuring the difference between $\mathrm{VC}$ and FVC in 1,084 individuals who underwent spirometry and plethysmography. The authors observed a higher difference (VC-FVC) in patients who had airflow obstruction than in "healthy" individuals $(140.9 \mathrm{~mL} \pm 9.20$ vs $79.3 \mathrm{~mL} \pm 7.61$, respectively, $P<0.001)$. Whether such a difference can be sufficiently discerning in the absence of physiologically defined COPD remains to be determined. However, a further study has suggested that a reduced $\mathrm{FEV}_{1}$ in the presence of normal $\mathrm{FEV}_{1} / \mathrm{VC}$ ratio may also reflect airflow limitation in the small airways, ${ }^{27}$ although further validation is clearly necessary.

\section{Single breath washout}

The concept of early closure of the small airways during exhalation has been exploited in the past by observing the gas composition during different stages of a total expiration. The single breath washout test is performed by inhaling $100 \%$ oxygen from residual volume (RV) to total lung capacity (TLC), then expiring slowly $(0.4-0.5 \mathrm{~L} / \mathrm{s})$ to $\mathrm{RV}$ again. ${ }^{28}$ Analysis of the nitrogen concentration throughout this expiration is quadriphasic, with Phase I containing negligible nitrogen (anatomical dead space), Phase II involving a short rapid increase in nitrogen (bronchial phase), Phase III involving a continued, more gradual rise in nitrogen (alveolar phase) and Phase IV involving a short final rapid rise in nitrogen (airway closure). Closing volume (CV) is the volume of gas left to expire when peripheral airway closure begins. ${ }^{29}$ If RV is known, the closing capacity (CC), which is the volume of gas remaining in the lungs and airways at this point, can also be calculated as the sum of RV and CV. A typical plot of expired gas versus volume is shown in Figure 2.

In healthy adults, $\mathrm{CV}$ occurs at low lung volumes (shortly before the endpoint of expiration) as a result of gravitydependant pleural pressure. ${ }^{28}$ In obstructive lung disease, $\mathrm{CV}$ is increased due to premature airway closure, which can occur for several reasons (including loss of elastic recoil as part of the emphysema process and loss/occlusion of small airways). It has previously been shown that, by comparing the kinetics of different inert gases, patients with advanced emphysema can be distinguished from healthy individuals and those with other respiratory diseases (eg, asthma) by a differential Phase II (a more pronounced separation of helium and sulfur hexafluoride). ${ }^{30}$ In early disease, however, most of the GOLD Stage 0 smokers exhibit increased Phase III slope, with further progressive increases from GOLD Stages I-IV, ${ }^{31}$ suggesting that the analysis of this phase may be a more useful 


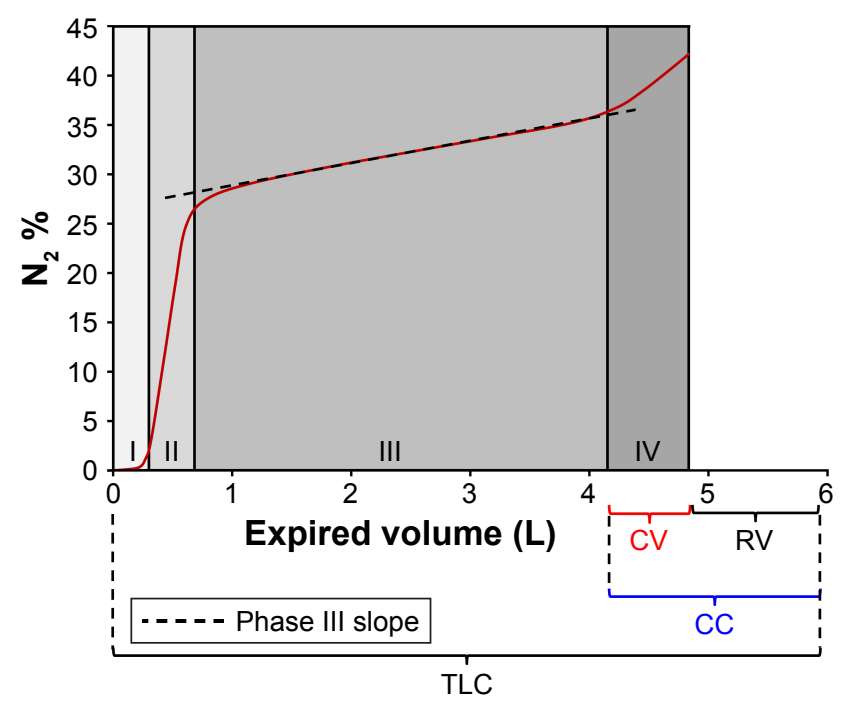

Figure 2 A typical plot of exhaled volume versus nitrogen concentration $\left(\mathrm{N}_{2} \%\right)$ obtained during the single breath nitrogen washout test.

Note: Stages I-IV (including the Phase III slope) are indicated, and the volume relationship between CV, CC, RV and TLC is also shown.

Abbreviations: CC, closing capacity; CV, closing volume; RV, residual volume; TLC, total lung capacity.

indicator of airway pathology before overt COPD develops. Buist and Ross ${ }^{32}$ recorded abnormal CV measurements (in relation to VC) in $44 \%$ of male and $36 \%$ of female smokers, whereas $\mathrm{FEV}_{1}$ was abnormal in only $12 \%$ of both sexes. CV increases disproportionately with age in smokers, ${ }^{33}$ suggesting that it is a sensitive indicator of small airways damage. This theory has been further supported by more recent studies that show $\mathrm{CV}$ not only correlates with $\mathrm{FEV}_{1} / \mathrm{FVC}^{34}$ but is also a more sensitive test of early lung damage than $\mathrm{FEV}_{1} \cdot{ }^{35}$

Recently, a new method of assessing single breath washout during tidal breathing has been developed. ${ }^{36}$ The test is based on the differential distribution of the two inhaled tracer gases (helium and sulfur hexafluoride). The outcome is a "tidal Phase III slope", and subsequent studies demonstrated that it has good reproducibility in the limited cohorts of healthy individuals and patients with COPD studied ${ }^{37}$ and it is a sensitive marker of small airways function in moderateto-severe COPD ${ }^{38}$ However, the test and its interpretation are still in development and further validation will be required before it can be implemented and interpreted clinically.

\section{Multiple breath washout}

The measurement of lung volumes by multiple breath washout was first described $>50$ years ago ${ }^{39}$ and involves the washout of an inert tracer gas (typically nitrogen or sulfur hexafluoride) by breathing $100 \%$ oxygen during relaxed, tidal ventilation. The lung clearance index (LCI) is calculated by dividing the functional residual capacity
(FRC) by the cumulative expired volume (the total volume of expired gas during the test). LCI is an assessment of ventilation heterogeneity and, consequently, increases with the severity of airflow obstruction. LCI has shown to be a sensitive and repeatable measure of airways disease, ${ }^{40-42}$ and importantly, Kraemer et al ${ }^{43}$ demonstrated that it was the first of many lung function parameters (including the traditional tests) to decline in children with cystic fibrosis, supporting its value in detecting early anatomical change. However, the usefulness of LCI in COPD has yet to be fully explored.

Analysis of the Phase III slope of the multiple breath washout curve represents intrinsic airway structure. ${ }^{44,45}$ It allows the determination of differentiation of ventilation heterogeneity between the larger, conducting airways $\left(S_{\text {cond }}\right)$ and, importantly, the small airways in the acinar region $\left(S_{\text {acin }}\right)$. Studies have demonstrated that both $S_{\text {cond }}$ and $S_{\text {acin }}$ are increased in established $\mathrm{COPD}^{46}$ but can also detect small airway abnormalities at the acinar entrance in patients with a lower smoking history ( $\geq 10$ pack years) than spirometry ( $\geq 20$ pack years). Other studies in asthma ${ }^{47}$ and bronchiolitis obliterans syndrome ${ }^{48}$ suggest that $S_{\text {acin }}$ may be a useful physiological marker of small airways function. However, its sensitivity to early small airways pathology is controversial, as one recent study demonstrated that $S_{\text {acin }}$ only became significantly higher than in never-smokers or smoking control subjects once GOLD Stage II COPD had developed (although the results of the GOLD Stage I cohort may have been underpowered). ${ }^{49}$

Although multiple breath washout tests are non-volitional, they are far more time consuming than single breath techniques, particularly when a tracer gas must first be washed into the lungs before being washed out (as with sulfur hexafluoride). Another challenge is the standardization of techniques, as different tracer gases have different physical properties and wash out of the lungs at different rates, yielding different results. ${ }^{50}$ Nevertheless, multiple breath washout tests are already widely implemented clinically for cystic fibrosis ${ }^{51}$ and a recent study has also shown that LCI may also be clinically useful as an indicator of early disease in AATD before spirometry becomes abnormal. ${ }^{52}$

\section{Airways resistance}

Spirometry has been generally considered as the gold standard method by which abnormal airflow limitation is diagnosed and assessed. However, the development of airflow limitation is multifactorial and an increase in Raw by direct measurement can potentially provide further information on airway function. Raw is measured by body plethysmography and relates airflow to driving pressure during tidal ventilation, 
although it is not routinely reported or used for interpretation. Raw is measured in conjunction with a technically demanding measurement of thoracic gas volume (TGV). ${ }^{53-56}$ In contrast, specific Raw (sRaw) can be obtained during non-volitional tidal ventilation. sRaw is derived from the specific resistance loop using a line of best fit (specific effective resistance [sReff]), the line connecting the maximum difference in shift volume (specific total resistance [sRtot]) or, less commonly, the line connecting expiratory flow between 0.5 and $-0.5 \mathrm{~L} / \mathrm{s}$. In healthy individuals (where the sRaw loop is linear), these three parameters are essentially equivalent, but in airflow obstruction, hysteresis of the sRaw loop leads to differences in sReff, sRtot and specific resistance at the flow of 0.5 litres per second (sR0.5) (Figure 3). Both sReff and sRtot are established measures of Raw, ${ }^{57,58}$ and one recent study in COPD suggested that both are reliable measures of peripheral airway function that relate to symptoms of dyspnea. ${ }^{59}$

The inverse of sRaw is specific airway conductance (sGaw), which is often considered as a more robust measure than Raw or sRaw due to its linear relationship with lung volume. ${ }^{60}$ Studies of Raw/conductance in COPD are also limited, although one early study demonstrated a marked reduction in Raw and sGaw in AATD patients with physiologically established airflow obstruction. ${ }^{61}$ Furthermore, sGaw is significantly reduced in chronic heavy smokers before airway obstruction is demonstrable by spirometry, ${ }^{62}$ again supporting airway changes undetected by conventional tests in early (or "pre") COPD. In addition, one study demonstrated that sGaw decreased before $\mathrm{FEV}_{1}$ in post-transplant bronchiolitis

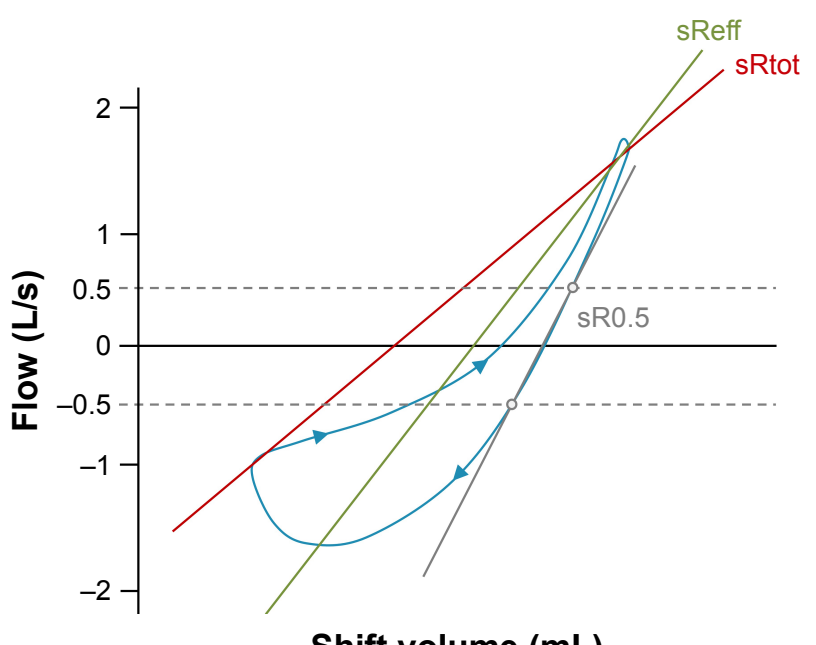

Shift volume $(\mathrm{mL})$

Figure 3 A typical sRaw loop in a patient with airflow obstruction, where shift volume is plotted against airflow.

Note: Hysteresis due to airflow obstruction highlights the differential derivation of sRaw using the sReff, sRtot and sR0.5 methods in these patients.

Abbreviations: sRaw, specific airway resistance; sReff, specific effective resistance; sRtot, specific total resistance; sR0.5, specific resistance at the flow of 0.5 litres per second.

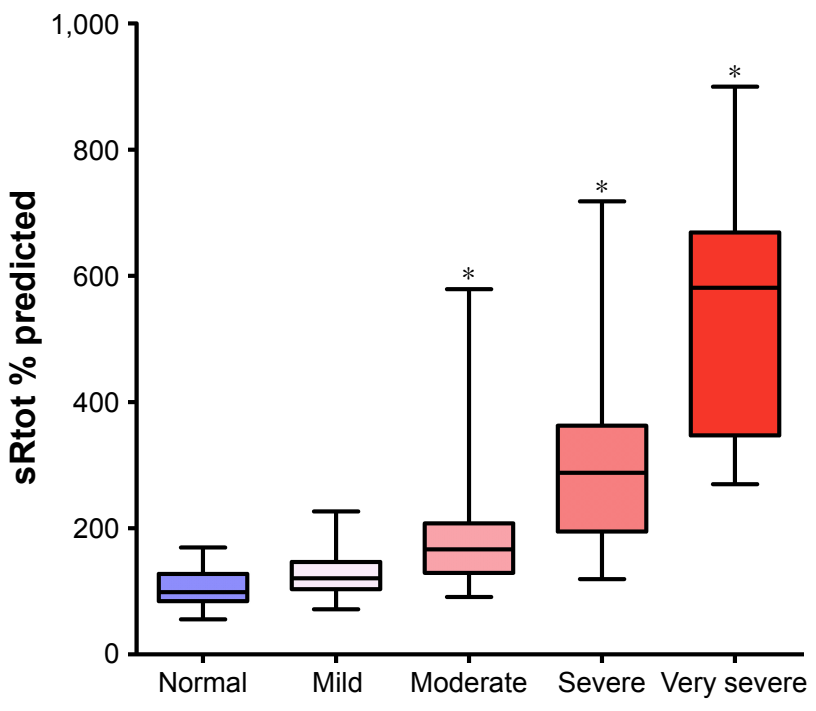

Figure 4 sRtot percentage predicted in 254 AATD patients with normal spirometry and varying degrees of airflow obstruction: mild (GOLD Stage I), moderate (GOLD Stage II), severe (GOLD Stage III) and very severe (GOLD Stage IV).

Note: *Significantly different from patients with normal spirometry $(P<0.00 \mathrm{I})$.

Abbreviations: AATD, alpha-I antitrypsin deficiency; GOLD, the Global Initiative for Chronic Obstructive Lung Disease; sRtot, specific total resistance.

obliterans syndrome, leading to support that sGaw is a more sensitive measure of small airways dysfunction than $\mathrm{FEV}_{1} \cdot{ }^{63}$ However, plethysmographic measures of Raw/conductance may be affected by airflow limitation anywhere in the respiratory tract and the evidence for usefulness of these parameters as a marker of small airways function in early COPD is uncertain. For example, it has also been shown that sRaw does not increase significantly (compared to people with normal spirometry) until moderate (GOLD Stage II) airflow obstruction has developed in AATD (Figure 4). ${ }^{64}$

\section{Oscillometry}

The forced oscillometry technique (FOT) and impulse oscillometry (IOS) are entirely non-volitional methods for assessing airway impedance (pressure/flow signal) by emitting oscillatory pressures of different frequencies (commonly between 5 and $35 \mathrm{~Hz}$ ) into the respiratory tract during tidal ventilation. The different frequencies allow for independent assessment of both proximal and peripheral airway mechanics. ${ }^{65-67}$ Higher frequencies (eg, $20 \mathrm{~Hz}$ ) do not penetrate deeply and relate to proximal airway function, whereas lower frequencies (eg, $5 \mathrm{~Hz}$ ) penetrate further and also include peripheral airway function. Consequently, the difference in resistance measurements (R5-R20) has been used as a surrogate marker to define peripheral Raw. The reactance at $5 \mathrm{~Hz}$ (X5) assesses the structural properties (inertia and capacitance) of the peripheral lung parenchyma and changes concordantly with variations in elasticity. ${ }^{65,66,68-70}$ The resonant frequency (Fres) is the frequency $(\mathrm{Hz})$ at which 
reactance is zero (when inertia and capacitance are equal). Importantly, X5 correlates well with more traditional measures of lung function such as spirometry. ${ }^{71}$

The ability to isolate peripheral airway function by using an effort-independent method is of importance, as it not only assesses the small airways but also is independent of effortrelated patient variability. Studies indicate that IOS not only is a useful measure of small airway function in $\mathrm{COPD}^{72-74}$ but may also be more sensitive to early COPD than spirometry both cross-sectionally ${ }^{75}$ and longitudinally. ${ }^{71}$ Interest in FOT (the original oscillometry technique) has recently increased with the development of both greatly improved FOT technology and a more robust normal reference range. ${ }^{76}$ Newer devices also allow the differentiation of inspiratory and expiratory mechanics, while including other parameters such as expiratory flow limitation. Studies with modern FOT devices have shown that they may be sensitive to very early smoking-induced small airway changes ${ }^{77,78}$ and useful for prospective monitoring in COPD. ${ }^{79}$

Therefore, the evidence that FOT can accurately isolate small airways function is promising but has yet to be fully evaluated, particularly as a marker of small airways dysfunction in early COPD. However, the clinical usefulness of FOT has been demonstrated in a number of studies where it has helped differentiate between COPD and asthma ${ }^{80}$ and has provided a clinically valuable means of monitoring changes in the small airways more sensitively than spirometry, following bronchial challenge ${ }^{81}$ or bronchodilator therapy. ${ }^{82}$ FOT may also be a useful and more appropriate tool for monitoring COPD patients during exacerbation ${ }^{83,84}$ and following airway clearance therapy. ${ }^{85}$ Further support for FOT as a useful physiological tool in clinical practice has been highlighted in recent clinical trials of bronchodilator therapy in COPD. ${ }^{86}$

\section{Computed tomography}

Computed tomography is being increasingly explored in understanding the clinical phenotype, pathophysiology and progression of COPD. It is the most direct, noninvasive way to assess the presence, type and distribution of emphysema. This is based on the loss of tissue and dilation of alveolar airspaces as a part of the emphysema process, which results in a reduction in lung density that can be quantified by objective analysis of the density data from the scanner. As emphysema develops and progresses, lung density measured at full inspiration reduces, closer to the density of air. Pathological studies have shown that emphysema is related to regions of the lung where density is $<-950$ hounsfield units (HU). ${ }^{87}$ The presence of emphysema relates to both the subsequent rate of decline of $\mathrm{FEV}_{1}^{7,8}$ and mortality. ${ }^{9}$ Furthermore, the progressive loss of density is the most direct and sensitive measure of emphysema progression ${ }^{88}$ and, for this reason, has been included as the primary outcome for several interventional studies to study disease-modifying therapies. ${ }^{89-91}$

Landmark pathological studies with high radiation dose micro-computed tomography (CT) analysis have provided evidence that the loss of small airways is an early event preceding the development of emphysema. With the continuing development of $\mathrm{CT}$ analysis, there have been several recent publication investigating the ability of CT to determine the presence of small airways disease and accurately quantify it. This is based on the concept that excess air trapping on expiration is a result of loss or premature closure of the small airways. Thus, on a scan performed at full expiration (RV), low density lung voxels $(<-856 \mathrm{HU})$ identify incomplete emptying of the lung. In contrast, low density lung voxels $(<-950 \mathrm{HU})$ on a scan performed at full inspiration (TLC) identify areas of emphysema. Analysis of inspiratory and expiratory CT data by parametric response mapping (PRM) can, therefore, potentially quantify air trapping due to small airways disease.

Although this concept seems reasonable, validation is urgently required to provide confidence that this methodology is both specific to the small airways and reproducible. For instance, in the publication by Bhatt et al, ${ }^{92}$ the expiratory scan was measured at FRC rather than RV, which will still contain low attenuation areas that are, at least in part, dilated air spaces due to emphysema and not the sole result of air trapping due to loss/closure of small airways that would be best identified and quantified at RV. Furthermore, achieving and maintaining the breath at RV reproducibly for initial and follow-up scan is difficult, especially in the presence of established COPD. This is demonstrated in a study by Sieren et al, ${ }^{93}$ where the average change in RV determined by volumetric analysis of scans from 952 subjects at baseline and 1 year later was $+35 \mathrm{~mL}$ on average but with an SD of $\pm 470 \mathrm{~mL}$. This enormous variation was seen despite careful methodology, the use of phantoms, adjustment for body mass index and standardized patient instructions. The variation was also noted to be extreme more frequently than scans at TLC. Nevertheless, in a recent follow-up publication by Martinez et $\mathrm{al}^{94}$ of 580 never- and ever-smokers with normal spirometry, there was an age-dependent increase in the PRM indicative of small airways disease that would be consistent with the concept of the "aging lung". How this differs from the "premature aging" of the early pathological and physiological changes of the COPD lung remains to be determined.

Small airway function has also been assessed in asthma using an alternative $\mathrm{CT}$ technique. Vos et $\mathrm{al}^{95}$ used a computer 
model to reconstruct a $3 \mathrm{D}$ image of the small airways (1-2 mm) at both TLC and FRC. By calculating the difference in small airway volume from TLC to FRC, the internal airflow and, hence, small Raw was derived. It is worth noting that this technique did not allow the assessment of airways $<1 \mathrm{~mm}$ in diameter, so inclusion of all small airways was not possible. However, it seems logical that it could also be used in COPD as a useful method of assessing (at least in part) small airway function.

These studies, although interesting, clearly need more validation of data acquisition and longitudinal studies to determine any clinical usefulness as well as the complex analysis and radiation exposure to patients that may limit the usefulness and generalizability. IfCT techniques (particularly PRM) do prove robust, it would allow the relationships between a quantifiable measure of small airways disease and physiological measures of small airway function to be determined for the first time.

\section{Assessing therapeutic response}

When assessing the effects of therapy in COPD (eg, bronchodilators) for general clinical management or clinical trials, spirometric parameters (particularly the $\mathrm{FEV}_{1}$ ) are usually the primary outcome. However, spirometry has a number of limitations, particularly in COPD where airflow obstruction often tends to be "fixed". It is well documented that bronchodilators can improve airway caliber (hence ventilation) over the tidal breathing range in COPD, leading to reduced hyperinflation, reduced work of breathing and symptomatic improvement in the absence of a significant spirometric response. ${ }^{96}$

The ability of small airways tests to detect physiological change following bronchodilation with greater sensitivity than spirometry has been robustly demonstrated in both asthma ${ }^{97}$ and COPD. ${ }^{98}$ Most notably in COPD, IOS measures of R5 and X5 and also plethysmographic Raw and sGaw

Table I Methodologies to assess small airways function

\begin{tabular}{|c|c|c|c|}
\hline Test & Strengths & Weaknesses & Change in COPD \\
\hline Expiratory flows & $\begin{array}{l}\text { I. Nonspecialized kit } \\
\text { 2. Widely available } \\
\text { 3. Integral to spirometry }\end{array}$ & $\begin{array}{l}\text { I. Highly effort dependent } \\
\text { 2. Results variable } \\
\text { 3. Wide "normal" range } \\
\text { 4. Requires careful interpretation }\end{array}$ & $\downarrow M M E F, \downarrow M^{\prime} F_{25}$ \\
\hline Single breath washout & $\begin{array}{l}\text { I. Overall assessment of ventilation } \\
\text { heterogeneity (Phase III slope) } \\
\text { 2. Quick to perform } \\
\text { 3. Novel double tracer gas method } \\
\text { requires only tidal breathing }\end{array}$ & $\begin{array}{l}\text { I. Classical method is effort dependent } \\
\text { 2. CV may be less informative about small airways } \\
\text { 3. Double tracer gas method not fully validated }\end{array}$ & $\begin{array}{l}\uparrow \text { Phase III slope } \\
\uparrow \mathrm{CV}, \uparrow \mathrm{CC}\end{array}$ \\
\hline Multiple breath washout & $\begin{array}{l}\text { I. Assessment of acinar and small } \\
\text { conducting airway ventilation } \\
\text { 2. Effort independent } \\
\text { 3. Evidence suggests that it is } \\
\text { sensitive to detection of early } \\
\text { disease }\end{array}$ & $\begin{array}{l}\text { I. Time consuming } \\
\text { 2. Results can be variable } \\
\text { 3. Different tracer gases yield different results } \\
\text { 4. Limited information on normal range for older } \\
\text { adults }\end{array}$ & $\uparrow \mathrm{LCl}, \uparrow \mathrm{S}_{\text {cond }}, \uparrow \mathrm{S}_{\text {acin }}$ \\
\hline Plethysmography & $\begin{array}{l}\text { I. sRaw is effort independent } \\
\text { 2. Quick test }\end{array}$ & $\begin{array}{l}\text { I. Achievement of TGV for Raw derivation can be } \\
\text { technically demanding } \\
\text { 2. Not specific to small airway function } \\
\text { 3. Sensitivity to early disease disputable }\end{array}$ & $\uparrow$ Raw, $\uparrow$ sRaw, $\downarrow$ sGaw \\
\hline Oscillometry & $\begin{array}{l}\text { I. Quick and effort independent } \\
\text { 2. Robust normal range } \\
\text { 3. Specific to small airway function } \\
\text { (particularly new FOT systems) } \\
\text { 4. Clinically validated - many } \\
\text { studies support usefulness }\end{array}$ & I. Specialized equipment & $\begin{array}{l}\text { Early: } \downarrow \text { X5 only } \\
\text { Advanced: } \uparrow \text { R5 and } \downarrow \text { X5 }\end{array}$ \\
\hline $\mathrm{CT}$ & $\begin{array}{l}\text { I. Allows direct quantification of } \\
\text { the presence of disease } \\
\text { 2. Gold standard for identifying and } \\
\text { quantifying emphysema } \\
\text { 3. Preliminary studies of inspiratory/ } \\
\text { expiratory CT offer promise }\end{array}$ & $\begin{array}{l}\text { I. Exposure to radiation prohibits regular } \\
\text { assessment } \\
\text { 2. Expensive } \\
\text { 3. Requires specialist centers and analysis } \\
\text { 4. Achieving consistent RV is difficult } \\
\text { 5. Inspiratory/expiratory method not fully validated }\end{array}$ & $\begin{array}{l}\text { Areas of low density at } \\
\text { TLC indicate emphysema } \\
\text { Additional areas of low } \\
\text { density at RV indicate } \\
\text { small airways disease }\end{array}$ \\
\hline
\end{tabular}

Notes: The table illustrates the different techniques currently available to assess small airways function and their strengths and weaknesses as well as pattern of change classically seen in COPD.

Abbreviations: CC, closing capacity; CV, closing volume; FOT, forced oscillometry technique; LCl, lung clearance index; MMEF, maximal mid-expiratory flow; Raw, airway resistance; $\mathrm{MEF}_{25}$, maximal expiratory flow when $25 \%$ of forced vital capacity remains; $S_{\text {cond, }}$, conductive airway heterogeneity; $S$, acinar airway heterogeneity; $X 5$, reactance at $5 \mathrm{~Hz}$; R5, resistance at $5 \mathrm{~Hz}$; RV, residual volume; sGaw, specific airway conductance; sRaw, specific airway resistance; TGV, thoracic gas volume; TLC, total lung capacity. 
showed higher sensitivity (accounting for within-test and day-to-day variabilities) to salbutamol response, than $\mathrm{FEV}_{1}$. Improvements in airways resistance (R5 and Raw) are due to an increase in airway caliber. The reason for improved lung reactance (X5) is less apparent but may be due to reduced hyperinflation following bronchodilation of the small airways and a consequent improvement in lung compliance. MMEF was also assessed but only showed an improvement at higher doses, which was then lost at subsequent doses. The variability in MMEF may be due to changes in FVC following bronchodilation, which can cause MMEF to shift. For this reason, it may be more useful to adjust MMEF for lung volume when assessing therapeutic response, as mentioned previously. ${ }^{21,22}$

The clinical usefulness of assessing bronchodilator response in early COPD is debatable, as current guidelines generally recommend the commencement of bronchodilators once physiologically established COPD has developed. ${ }^{14}$ However, it is important to appreciate that spirometry is limited and tests of small airways function may be a more sensitive and robust method of detecting physiological change than $\mathrm{FEV}_{1}$, particularly in clinical trials.

\section{Summary and conclusion}

There is increasing recognition that diagnosing lung diseases in the earliest stages may offer valuable insight into pathogenesis and provide a better opportunity to intervene in the natural history of the disease, thus improving longterm patient outcomes. Both physiological and pathological studies suggest that small airways damage and dysfunction may precede airflow obstruction and emphysema and may, therefore, provide a signal of early disease in COPD.

The assessment of small airways physiology is not a new concept, and over time, a number of methodologies have emerged that have sought to provide information about small airways function. These are summarized in Table 1, which also describes the potential strengths and limitations of each approach.

Historically, it has proven difficult to obtain specific measurements of small airway function and, consequently, available techniques had been largely abandoned for general clinical management (where disease is usually well established). However, as Table 1 summarizes, new methods as well as improved technologies for existing tests have recently emerged that may prove more useful especially in the identification of early disease before the spirometric criterion defining COPD is reached. Certainly, some of these physiological tests have demonstrated a degree of usefulness both clinically and as research tools to answer or explore several pathophysiological questions. If these methods can ultimately prove sensitive to small airways dysfunction and progressive lung damage, they may aid the diagnosis of early disease (preCOPD) and also potentially improve the ability to monitor, prevent or abrogate long-term clinical outcomes.

\section{Acknowledgments}

The Alpha-1 Foundation provided salary support to JAS during the writing of this review as part of project grant assessing small airways in AATD. RAS and ES are the joint senior authors.

\section{Disclosure}

The authors report no conflicts of interest in this work.

\section{References}

1. Hogg JC, Macklem PT, Thurlbeck WM. Site and nature of airway obstruction in chronic obstructive lung disease. $N$ Engl J Med. 1968; 278(25):1355-1360.

2. Bosken CH, Wiggs BR, Pare PD, Hogg JC. Small airway dimensions in smokers with obstruction to airflow. Am Rev Respir Dis. 1990; 142(3):563-570.

3. Nagai A, West WW, Thurlbeck WM. The national institutes of health intermittent positive-pressure breathing trial: pathology studies. II. Correlation between morphologic findings, clinical findings, and evidence of expiratory air-flow obstruction. Am Rev Respir Dis. 1985; 132(5):946-953.

4. Olofsson J, Bake B, Svardsudd K, Skoogh BE. The single breath N2-test predicts the rate of decline in FEV1. The study of men born in 1913 and 1923. Eur J Respir Dis. 1986;69(1):46-56.

5. Stanescu DC, Rodenstein DO, Hoeven C, Robert A. "Sensitive tests" are poor predictors of the decline in forced expiratory volume in one second in middle-aged smokers. Am Rev Respir Dis. 1987;135(3):585-590.

6. Buist AS, Vollmer WM, Johnson LR, McCamant LE. Does the singlebreath N2 test identify the smoker who will develop chronic airflow limitation? Am Rev Respir Dis. 1988;137(2):293-301.

7. Nishimura M, Makita H, Nasuhara Y, Hizawa N, Betsuyaku T. Phenotype characterization based upon high-resolution computed tomography findings and reversibility of airflow limitation in chronic obstructive pulmonary disease. Proc Am Thorac Soc. 2006;3(6):544.

8. Mohamed Hoesein FA, de Hoop B, Zanen P, et al. CT-quantified emphysema in male heavy smokers: association with lung function decline. Thorax. 2011;66(9):782-787.

9. Oelsner EC, Hoffman EA, Folsom AR, et al. Association between emphysema-like lung on cardiac computed tomography and mortality in persons without airflow obstruction: a cohort study. Ann Intern Med. 2014;161(12):863-873.

10. de Torres JP, Bastarrika G, Wisnivesky JP, et al. Assessing the relationship between lung cancer risk and emphysema detected on low-dose CT of the chest. Chest. 2007;132(6):1932-1938.

11. Hogg JC, Chu F, Utokaparch S, et al. The nature of small-airway obstruction in chronic obstructive pulmonary disease. $N$ Engl J Med. 2004; 350(26):2645-2653.

12. McDonough JE, Yuan R, Suzuki M, et al. Small-airway obstruction and emphysema in chronic obstructive pulmonary disease. $N$ Engl J Med. 2011;365(17):1567-1575.

13. Stockley JA, Ismail A, Hughes SM, Edgar RE, Stockley RA, Sapey E. Mid maximal expiratory flow detects early lung disease in alpha 1 anti-trypsin deficiency. Eur Respir J. 2017;49:3. 
14. Vogelmeier CF, Criner GJ, Martinez FJ, et al. Global strategy for the diagnosis, management, and prevention of chronic obstructive lung disease 2017 report: GOLD executive summary. Am J Respir Crit Care Med. 2017;195(5):557-582.

15. Carter RI, Ungurs MJ, Mumford RA, Stockley RA. A $\alpha-V a 1360$ : a marker of neutrophil elastase and COPD disease activity. Eur Respir J. 2012;41(1):31.

16. Hogg JC, McDonough JE, Sanchez PG, et al. Micro-computed tomography measurements of peripheral lung pathology in chronic obstructive pulmonary disease. Proc Am Thorac Soc. 2009;6(6) 546-549.

17. Leuallen EC, Fowler WS. Maximal midexpiratory flow. Am Rev Tuberc. 1955;72(6):783-800.

18. Tsushima K, Sone S, Hanaoka T, Takayama F, Honda T, Kubo K. Comparison of bronchoscopic diagnosis for peripheral pulmonary nodule under fluoroscopic guidance with CT guidance. Respir Med. 2009; 100(4):737-745.

19. Mirsadraee M, Boskabady MH, Attaran D. Diagnosis of chronic obstructive pulmonary disease earlier than current global initiative for obstructive lung disease guidelines using a feasible spirometry parameter (maximal-mid expiratory flow/forced vital capacity). Chron Respir Dis. 2013;10(4):191-196.

20. Quanjer PH, Weiner DJ, Pretto JJ, Brazzale DJ, Boros PW. Measurement of FEF $25-75 \%$ and FEF75\% does not contribute to clinical decision making. Eur Respir J. 2014;43(4):1051-1058.

21. Newball HH. The unreliability of the maximal midexpiratory flow as an index of acute airway changes. Chest. 1975;67(3):311-314.

22. Sherter CB, Connolly JJ, Schilder DP. The significance of volumeadjusting the maximal midexpiratory flow in assessing the response to a bronchodilator drug. Chest. 1978;73(5):568-571.

23. Topalovic M, Exadaktylos V, Decramer M, Berckmans D, Troosters T, Janssens W. Using dynamics of forced expiration to identify COPD where conventional criteria for the FEV1/FVC ratio do not match Respirology. 2015;20(6):925-931.

24. Saltzman HP, Ciulla EM, Kuperman AS. The spirographic "kink". A sign of emphysema. Chest. 1976;69(1):51-55.

25. Chan ED, Irvin CG. The detection of collapsible airways contributing to airflow limitation. Chest. 1995;107(3):856-859.

26. Barros AR, Pires MB, Raposo NM. Importance of slow vital capacity in the detection of airway obstruction. J Bras Pneumol. 2013;39(3): 317-322.

27. Stanescu D, Veriter C. A normal FEV1/VC ratio does not exclude airway obstruction. Respiration. 2004;71(4):348-352.

28. Anthonisen NR, Robertson PC, Ross WR. Gravity-dependent sequential emptying of lung regions. J Appl Physiol. 1970;28(5):589.

29. Dollfuss RE, Milic-Emili J, Bates DV. Regional ventilation of the lung studied with boluses of 133xenon. Respir Physiol. 1967;2(2):234-264.

30. Worth H, Smidt U. Phase II of expiratory curves of respiratory and inert gases in normals and in patients with emphysema. Bull Eur Physiopathol Respir. 1982;18(2):247-253.

31. Gennimata SA, Palamidas A, Karakontaki F, et al. Pathophysiology of evolution of small airways disease to overt COPD. COPD. 2010;7(4): 269-275.

32. Buist AS, Ross BB. Quantitative analysis of the alveolar plateau in the diagnosis of early airway obstruction. Am Rev Respir Dis. 1973;108(5): 1078-1087.

33. Buist AS, Ross BB. Predicted values for closing volumes using a modified single breath nitrogen test. Am Rev Respir Dis. 1973;107(5): 744-752.

34. Timmins SC, Diba C, Farrow CE, et al. The relationship between airflow obstruction, emphysema extent, and small airways function in COPD. Chest. 2012;142(2):312-319.

35. Garcia G, Perez T, Verbanck S. Functional measurements of the peripheral airways in COPD. Rev Mal Respir. 2012;29(2):319-327.

36. Singer F, Stern G, Thamrin C, et al. A new double-tracer gas single-breath washout to assess early cystic fibrosis lung disease. Eur Respir J. 2013; 41(2):339.
37. Husemann K, Berg N, Engel J, et al. Double tracer gas single-breath washout: reproducibility in healthy subjects and COPD. Eur Respir J. 2014;44(5):1210.

38. Boeck L, Gensmer A, Nyilas S, et al. Single-breath washout tests to assess small airway disease in COPD. Chest. 2016;150(5):1091-1100.

39. Becklake MR. A new index of the intrapulmonary mixture of inspired air. Thorax. 1952;7(1):111-116.

40. Aurora P, Kozlowska W, Stocks J. Gas mixing efficiency from birth to adulthood measured by multiple-breath washout. Respir Physiol Neurobiol. 2005;148(1-2):125-139.

41. Lum S, Gustafsson P, Ljungberg H, et al; London Cystic Fibrosis Collaboration. Early detection of cystic fibrosis lung disease: multiple-breath washout versus raised volume tests. Thorax. 2007; 62(4):341

42. Horsley AR, Gustafsson PM, Macleod KA, et al. Lung clearance index is a sensitive, repeatable and practical measure of airways disease in adults with cystic fibrosis. Thorax. 2008;63(2):135-140.

43. Kraemer R, Delosea N, Ballinari P, Gallati S, Crameri R. Effect of allergic bronchopulmonary aspergillosis on lung function in children with cystic fibrosis. Am J Respir Crit Care Med. 2008;174(11):1211-1220.

44. Crawford AB, Makowska M, Paiva M, Engel LA. Convection- and diffusion-dependent ventilation maldistribution in normal subjects. J Appl Physiol. 1985;59(3):838-846.

45. Verbanck S, Larsson H, Linnarsson D, Prisk GK, West JB, Paiva M. Pulmonary tissue volume, cardiac output, and diffusing capacity in sustained microgravity. J Appl Physiol (1985). 1997;83(3):810-816.

46. Liu B, Zhou Q, He B. [The application of multiple breath nitrogen washout in chronic obstructive pulmonary disease]. Zhonghua Jie He Hе Hu Xi Za Zhi. 2015;38(7):492-496. Chinese.

47. Verbanck S, Schuermans D, Vincken W. Inflammation and airway function in the lung periphery of patients with stable asthma. $J$ Allergy Clin Immunol. 2010;125(3):611-666.

48. Thompson BR, Hodgson YM, Kotsimbos T, et al. Bronchiolitis obliterans syndrome leads to a functional deterioration of the acinus post lung transplant. Thorax. 2014;69(5):487-488.

49. Jarenback L, Ankerst J, Bjermer L, Tufvesson E. Acinar ventilation heterogeneity in COPD relates to diffusion capacity, resistance and reactance. Respir Med. 2016;110:28-33.

50. Jensen R, Stanojevic S, Gibney K, et al. Multiple breath nitrogen washout: a feasible alternative to mass spectrometry. PLoS One. 2013; 8(2):e56868.

51. Horsley A. Lung clearance index in the assessment of airways disease. Respir Med. 2009;103(6):793-799.

52. Fuchs SI, Schwerk N, Pittschieler K, et al. Lung clearance index for monitoring early lung disease in alpha-1-antitrypsin deficiency. Respir Med. 2016;116:93-99.

53. Tattersfield AE, Keeping IM. Assessing change in airway caliber measurement of airway resistance. Br J Clin Pharmacol. 1979;8(4): 307-319.

54. Kaminsky D, Irvin C. Lung function in asthma. In: Barnes P, Grunstein M, Leff A, Woolcock A, editors. Asthma. New York: Lippincott-Raven; 1997:1289

55. Blonshine S, Goldman MD. Optimizing performance of respiratory airflow resistance measurements. Chest. 2008;134(6):1304-1309.

56. Criee CP, Sorichter S, Smith HJ, et al; Working Group for Body Plethysmography of the German Society for Pneumology and Respiratory Care. Body plethysmography - its principles and clinical use. Respir Med. 2011;105(7):959-971.

57. Islam MS, Ulmer WT. Diagnostic value of "closing volume" in comparison to "airway resistance-lung volume plot". Respiration. 1974; 31(6):449-458.

58. Matthys H, Orth U. Comparative measurements of airway resistance. Respiration. 1975;32(2):121-134.

59. Mahut B, Caumont-Prim A, Plantier L, et al. Relationships between respiratory and airway resistances and activity-related dyspnea in patients with chronic obstructive pulmonary disease. Int J Chron Obstruct Pulmon Dis. 2012;7:165-171. 
60. Briscoe WA, Dubois AB. The relationship between airway resistance, airway conductance and lung volume in subjects of different age and body size. J Clin Invest. 1958;37(9):1279-1285.

61. Duncan PE, Griffin JP. Physiological studies in a large sibship with antitrypsin deficiency. Br J Dis Chest. 1975;69(2):107-117.

62. Nagelmann A, Tonnov A, Laks T, Sepper R, Prikk K. Lung dysfunction of chronic smokers with no signs of COPD. COPD. 2011;8(3): 189-195.

63. Bassiri AG, Girgis RE, Doyle RL, Theodore J. Detection of small airway dysfunction using specific airway conductance. Chest. 1997;111(6): 1533-1535.

64. Stockley J, Smith L, Cooper B, Stockley R, Sapey E. Specific airway resistance as a marker of early disease in alpha-1 antitrypsin deficiency. Eur Respir J. 2015;46(suppl 59):A960.

65. Hellinckx J, Cauberghs M, De Boeck K, Demedts M. Evaluation of impulse oscillation system: comparison with forced oscillation technique and body plethysmography. Eur Respir J. 2001;18(3):564-570.

66. King GG, Salome CM. Multimodality measurements of small airways disease. Eur Respir J. 2006;27(2):250-252.

67. Oppenheimer BW, Goldring RM, Herberg ME, et al. Distal airway function in symptomatic subjects with normal spirometry following World Trade Center dust exposure. Chest. 2007;132(4):1275-1282.

68. Goldman MD, Saadeh C, Ross D. Clinical applications of forced oscillation to assess peripheral airway function. Respir Physiol Neurobiol. 2005;148(1-2):179-194.

69. Smith HJ, Reinhold P. Forced oscillation technique and impulse oscillometry. Eur Respir Mon. 2005;31:72-105.

70. Nieto A, Pamies R, Oliver F, Medina A, Caballero L, Mazon A. Montelukast improves pulmonary function measured by impulse oscillometry in children with asthma (Mio study). Respir Med. 2006;100(7): 1180-1185.

71. Kolsum U, Borrill Z, Roy K, et al. Impulse oscillometry in COPD: identification of measurements related to airway obstruction, airway conductance and lung volumes. Respir Med. 2009;103(1):136-143.

72. Ohishi J, Kurosawa H, Ogawa H, Irokawa T, Hida W, Kohzuki M. Application of impulse oscillometry for within-breath analysis in patients with chronic obstructive pulmonary disease: pilot study. $B M J$ Open. 2011;1:2.

73. Tanaka H, Fujii M, Kitada J. [Further examination of COPD using spirometry, respiratory function test, and impulse oscillometry]. Nihon Rinsho. 2011;69(10):1786-1791.

74. Anderson WJ, Lipworth BJ. Relationships between impulse oscillometry, spirometry and dyspnoea in COPD. $J R$ Coll Physicians Edinb. 2012;42(2):111-115.

75. Oppenheimer BW, Goldring RM, Berger KI. Distal airway function assessed by oscillometry at varying respiratory rate: comparison with dynamic compliance. COPD. 2009;6(3):162-170.

76. Oostveen E, Boda K, van der Grinten CP, et al. Respiratory impedance in healthy subjects: baseline values and bronchodilator response. Eur Respir J. 2013;42(6):1513-1523.

77. Faria AC, Lopes AJ, Jansen JM, Melo PL. Evaluating the forced oscillation technique in the detection of early smoking-induced respiratory changes. Biomed Eng Online. 2009;8:22.

78. Faria AC, Costa AA, Lopes AJ, Jansen JM, Melo PL. Forced oscillation technique in the detection of smoking-induced respiratory alterations: diagnostic accuracy and comparison with spirometry. Clinics. 2010; 65(12):1295-1304.

79. Kamada T, Kaneko M, Tomioka H. Impact of exacerbations on respiratory system impedance measured by a forced oscillation technique in COPD: a prospective observational study. Int J Chron Obstruct Pulmon Dis. 2017;12:509-516.

80. Brashier B, Salvi S. Measuring lung function using sound waves: role of the forced oscillation technique and impulse oscillometry system. Breath (Sheff). 2015;11(1):57-65.
81. Kaminsky DA. What does airway resistance tell us about lung function? Respir Care. 2012;57(1):85-96; discussion 96-99.

82. Goldman MD, Nazeran H, Ramos C, et al. Electrical circuit models of the human respiratory system reflect small airway impairment measured by impulse oscillation (IOS). Conf Proc IEEE Eng Med Biol Soc. 2010;2010:2467-2472

83. Johnson MK, Birch M, Carter R, Kinsella J, Stevenson RD. Measurement of physiological recovery from exacerbation of chronic obstructive pulmonary disease using within-breath forced oscillometry. Thorax. 2007;62(4):299-306.

84. Jetmalani K, Timmins S, Brown NJ, et al. Expiratory flow limitation relates to symptoms during COPD exacerbations requiring hospital admission. Int J Chron Obstruct Pulmon Dis. 2010;10:939-945.

85. Figueiredo PH, Zin WA, Guimaraes FS. Flutter valve improves respiratory mechanics and sputum production in patients with bronchiectasis. Physiother Res Int. 2012;17(1):12-20.

86. Mineshita M, Shikama Y, Nakajima H, et al; COPD EXHALATION Investigators. The application of impulse oscillation system for the evaluation of treatment effects in patients with COPD. Respir Physiol Neurobiol. 2014;202:1-5.

87. Gevenois PA, Yernault JC. Can computed tomography quantify pulmonary emphysema? Eur Respir J. 1995;8(5):843-848.

88. Stolk J, Cooper BG, Stoel B, et al. Retinoid treatment of emphysema in patients on the alpha-1 international registry. The REPAIR study: study design, methodology and quality control of study assessments. Ther Adv Respir Dis. 2010;4(6):319-332.

89. Dirksen A, Dijkman JH, Madsen F, et al. A randomized clinical trial of alpha 1-antitrypsin augmentation therapy. Am J Respir Crit Care Med. 1999;160(5 pt 1):1468-1472.

90. Dirksen A, Piitulainen E, Parr DG, et al. Exploring the role of CT densitometry: a randomised study of augmentation therapy in alpha-1 antitrypsin deficiency. Eur Respir J. 2009;33(6):1345-1353.

91. Chapman KR, Burdon JG, Piitulainen E, et al; RAPID Trial Study Group. Intravenous augmentation treatment and lung density in severe alpha1 antitrypsin deficiency (RAPID): a randomised, double-blind, placebo-controlled trial. Lancet. 2015;386(9991):360-368.

92. Bhatt SP, Soler X, Wang X, et al; COPDGene Investigators. Association between functional small airway disease and FEV1 decline in chronic obstructive pulmonary disease. Am J Respir Crit Care Med. 2016; 194(2):178-184.

93. Sieren JP, Newell JD Jr, Barr RG, et al; SPIROMICS Research Group. SPIROMICS protocol for multicenter quantitative computed tomography to phenotype the lungs. Am J Respir Crit Care Med. 2016; 194(7):794-806.

94. Martinez CH, Diaz AA, Meldrum C, et al; SPIROMICS Investigators. Age and small airway imaging abnormalities in subjects with and without airflow obstruction in SPIROMICS. Am J Respir Crit Care Med. 2016;195(4):464-472.

95. Vos W, De Backer J, Poli G, et al. Novel functional imaging of changes in small airways of patients treated with extrafine beclomethasone/ formoterol. Respiration. 2013;86(5):393-401.

96. Newton MF, O’Donnell DE, Forkert L. Response of lung volumes to inhaled salbutamol in a large population of patients with severe hyperinflation. Chest. 2002;121(4):1042-1050.

97. Houghton CM, Woodcock AA, Singh D. A comparison of lung function methods for assessing dose-response effects of salbutamol. Br J Clin Pharmacol. 2004;58(2):134-141.

98. Borrill ZL, Houghton CM, Woodcock AA, Vestbo J, Singh D. Measuring bronchodilation in COPD clinical trials. Br J Clin Pharmacol. 2005;59(4):379-384 
International Journal of COPD

\section{Publish your work in this journal}

The International Journal of COPD is an international, peer-reviewed journal of therapeutics and pharmacology focusing on concise rapid reporting of clinical studies and reviews in COPD. Special focus is given to the pathophysiological processes underlying the disease, intervention programs, patient focused education, and self management protocols.

\section{Dovepress}

This journal is indexed on PubMed Central, MedLine and CAS. The manuscript management system is completely online and includes a very quick and fair peer-review system, which is all easy to use. Visit $\mathrm{http}: / / \mathrm{www}$.dovepress.com/testimonials.php to read real quotes from published authors.

Submit your manuscript here: http://www.dovepress.com/international-journal-of-chronic-obstructive-pulmonary-disease-journal 